International Journal of Current Advanced Research

ISSN: O: 2319-6475, ISSN: P: 2319 - 6505, Impact Factor: SJIF: 5.995

Available Online at www.journalijcar.org

Volume 6; Issue 5; May 2017; Page No. 3796-3801

DOI: http://dx.doi.org/10.24327/ijcar.2017.3801.0370

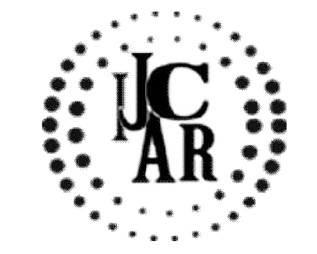

Research Article

\title{
INTELLIGENT SYSTEM FOR WHITE GRUB MONITORING THROUGH WSN WITH LabVIEW SOLUTION/INTERFACE SUPPORT
}

\section{Yusuf Saleh and Rashid Hussain}

Department of Electronics and Communication Engineering Suresh Gyan Vihar University Jaipur, Rajasthan, India

\section{A R T I C L E I N F O}

\section{Article History:}

Received $17^{\text {th }}$ February, 2017

Received in revised form $12^{\text {th }}$ March, 2017

Accepted $8^{\text {th }}$ April, 2017

Published online $28^{\text {th }}$ May, 2017

\section{Key words:}

Insecticide; location; Entomophatogenic nematodes (EPNs); Volatile; WSN; GMM 221

$\mathrm{CO}_{2}$ sensor; Acoustic; environmental conditions; monitor; LabVIEW.

\begin{abstract}
A B S T R A C T
The use of pesticide and insecticide pollutes the environment (soil, plants and beneficial living organisms in and above the soil). Therefore, to reduce effect of insecticide to human and the environment, biological control has been employed. White grub is larvae beneath the ground feeding on roots of crops and damaging it. The biggest challenge in either the use of pesticide or bio-agent is to know the exact location and time of early infestation for effective use of resources (bio-agent, pesticides, time and labor) and to reduce damage to crop. White grubs release burst of $\mathrm{CO}_{2}$ and this serves as an attractant for Entomophatogenic nematodes (EPNs) as a natural enemy. Other volatiles are emitted by roots of plants on attack by insects to serve as a specific signal to support the $\mathrm{CO}_{2}$ attractant. These challenges prompt the use of Wireless Sensor Network (WSN) to detect the burst of $\mathrm{CO}_{2}$ (GMM $221 \mathrm{CO}_{2}$ sensor), get exact location by Global Positioning System (GPS), and send a message of the location and time. $\mathrm{CO}_{2}$ is not reliable to quantify due to soil respiration. Acoustic technique (sound and vibration measurement suite via microphone) is utilized to support the detection of white grubs and exact location. Their behavior and lifecycle are monitored by environmental conditions (temperature, moisture, humidity and others) that influence their activities and behavior. The scope will provide a solution through Laboratory Virtual Instrument Engineering Workbench (LabVIEW) to display the parameters and monitored on real time with proper calibration and quantification of $\mathrm{CO}_{2}$ and volatile compound through visual/graphical programming in their engineering units and frequency pattern of sound with analysis and fully equipped WSN tools and kit from National Instrument-NI Texas, but no control action.
\end{abstract}

Copyright $₫ 2017$ Rashid Hussain and Yusuf Saleh. This is an open access article distributed under the Creative Commons Attribution License, which permits unrestricted use, distribution, and reproduction in any medium, provided the original work is properly cited.

\section{INTRODUCTION}

Wireless Sensor Network (WSN) is a network of clusters of sensors which sense a parameter, process and communicates to a server. The cluster contains sensor nodes which one or more sensors are attached and communicate with each other and route data. One of the sensor node technologies is Mica2 Mote developed by Crossbow Technology. WSN is applied in agriculture and food industry for farm field, green house and warehouse. WSN can be used in Environmental monitoring for animal tracking, forest surveillance, fire detection, landslide, flood detection, and weather forecasting of temperature, moisture, humidity and others alongside Geographic Information System (GIS) and Global Positioning System (GPS). WSN applications in precision agriculture makes possible to increase efficiencies, productivity and profitability [1].

\section{*Corresponding author: Rashid Hussain}

Department Of Electronics and Communication Engineering Suresh Gyan Vihar University Jaipur, Rajasthan, India
In pest control as the focus of this research, the insects like human and other living organisms depends on the environment condition for their activities and determine their behavior. Therefore, we study their behavior by monitoring these environmental conditions (temperature, moisture, humidity and others) that influence their activities and behavior and we apply detection techniques to alert farmer of their presence and take action only when it is needed to reduce labor. This is required for efficiency and effective use of resources to improve crop yield, productivity and profitability like in fertilizer application and water management in irrigation and green house.

\section{Background study}

These are insect pest that are hidden under the soil and very difficult to control. The techniques employed are destructive and laborious. There is need for and inexpensive and non destructive method of detection, quantifying the insect population underground and control, because these insect pest cause lots of expensive damages to crops. 


\section{WSN in Soil insect pest}

Insect pests in soil are hidden under ground and make damages to the plant roots while growing. Methods employed to detect such harmful insects includes; acoustic techniques, thermal imaging cameras and $\mathrm{CO}_{2}$ sensor or volatile compound sensor (as a foraging cue due to activity and as a natural attraction of enemy). Several other methods or techniques (image, video, optical sensors in the field and satellite, drone for airborne) for insect detection are available, but these are those known for their potentials for detection above the ground and in this case we want to detect insects below soil and cope with the challenges or difficulties.

White grubs are the larvae of beetles and caused a lot of damage to roots of plants or crops. $\mathrm{CO}_{2}$ is released in burst by the white grubs and this attracts or acts as a foraging cue for natural enemies (nematode) [2]. Therefore, $\mathrm{CO}_{2}$ sensor was used to detect the grubs, but remains a challenge to quantify the $\mathrm{CO}_{2}$ from the grubs. Acoustics technique will be used to support the detection. White grubs damage is shown below figure 1 . below.

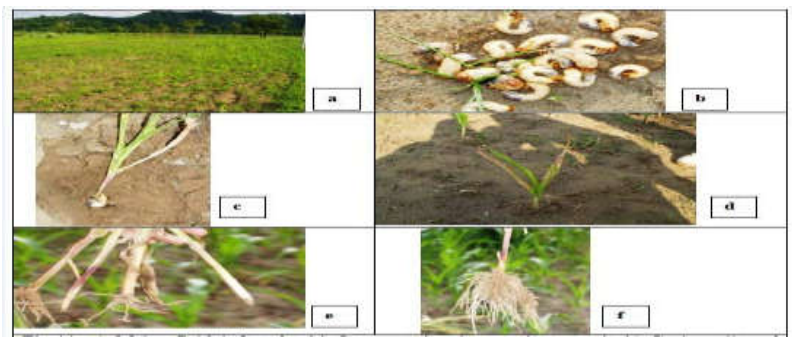

Fig. 1. White grub damage to maize roots [Photo taken in RARI]

Detection of sound made by these insects in feeding, communication and other movement is an approach to detect the insects hidden from view. The insects include; grubs, citrus weevil e.t.c. and there is need to study their behavior, life cycle and population. The approach of insect sound detection is called Acoustic technique. It is a user-friendly, non destructive technique. However, the precision to identify specific insect pests and their population is limited to high rate of attenuation of sound in the soil $\left(\sim 600 \mathrm{~dB} \mathrm{~m}^{-1}\right.$, compared with $\sim 0.008 \mathrm{~dB} \mathrm{~m}^{-1}$ in air) and lack of specific spectrum in the broad band.

The importance of acoustic technique to detect soil insect pests depends on signal-to-noise ratio, distortion and attenuation, the distinguishable sounds made by other organisms, and the fraction of the measurement period during which signals are generated (Mankin et al. 2016). Soil microphone and accelerometer (portable) were used in the field to detect grubs and weevils at distance of $20-50 \mathrm{~cm}$ or low frequency of $<5 \mathrm{kHz}$ at a distance of $5-50 \mathrm{~cm}$. Also tested for their (acoustic sensors) detection range and get signals features to distinguish pest from non-pest. There was success in generating spectral and temporal templates to distinguish insect sounds from background noise, between grubs, weevils and mole cricket, other pest insects and sound made by nonpest insect organisms (e.g., millipedes, earthworms, and earwigs). In the future acoustic technique will be inexpensive, estimate of insect population (count of insects) and trained listeners can sample exact location if insects' evidence is not precise [3].
To reduce pollution and hazard posed to human and the environment by the use of insecticide in agricultural fields, biological control has been employed, which is successful and widely used and under continues research. The research considered in this paper focus on white grub which is the larvae beneath the ground feeding on roots of crop and damaging it. It has four (4) stages in its lifecycle, from eggs to larvae stages $\left(1^{\text {st }}, 2^{\text {nd }}\right.$, and $3^{\text {rd }}$ instars $)$ and then to beetle, which goes above the ground and damage the stems or leafs. The $3^{\text {rd }}$ instar larvae stage under the soil does not respond to pesticide control and bio-agent is used.

Other volatiles are emitted by roots of plants on attack by insects to serve as a specific signal to support the $\mathrm{CO}_{2}$ attractant which its volume from white grub is affected by soil respiration from other organisms. The biggest challenge in either the use of pesticide or bio-agent is to know the exact location and time of early infestation. These factors will serve to make effective use of resources (bio-agent, pesticides, time and labor) and to reduce damage to crop. These challenges prompt the use of wireless sensor network (WSN) to detect the burst of $\mathrm{CO}_{2}$, get exact location by GPS, and send a message of the location and time. It is also a challenge to quantify the $\mathrm{CO}_{2}$ of the white grub, and is not reliable due to other amount of $\mathrm{CO}_{2}$ present from other sources. Acoustic technique is utilized to support the detection of white grubs and exact location.

\section{White Grub Behavior Monitoring through WSN}

The concept of white grub detection will be executed based on the combination of $\mathrm{CO}_{2}$, volatile compound and acoustic sensor systems to support each other for precise and accurate determination of exact location and infestation of white grubs under the soil. The soil or environmental conditions that influence the activities of these grubs such as temperature, humidity, soil moisture and soil PH will also be measured all to aid in studying the behavior and habitat of these grubs for better detection and control.

\section{Reviewed concept of $\mathrm{CO}_{2}$ and acoustics technique}

This sensor system will use the idea of foraging cues used by Entomopathogenic nematodes (EPNs) to locate host from the volatiles that are emitted by roots of plants under attack. Evidence from studies have shown that at longer distance, EPNs used the specific emitted volatiles to locate host (attracted to the volatile) and this idea of attraction towards the specific volatiles can be used such that the volatiles can be sensed or detected to indicate the presence and location of grub. Therefore, the plant root produced signal as a more specific root volatile in combination with $\mathrm{CO}_{2}$ as an attractant would be more attractive than either alone and can be stronger means of detecting the grubs presence with a volatile compound sensor. Chemicals emitted from host are good host location cues. The $\mathrm{CO}_{2}$ sensor for detecting the grubs is unreliable due to presence of the $\mathrm{CO}_{2}$ released by other organisms in the soil and posed a difficulty in quantifying it from the host alone. The idea of a generic signal in combination with more specific signal can be a highly effective way of finding host and resources.

Volatiles are emitted in large amounts by plants under insect attack. Studies have shown that EPNs were attracted to roots of plants after damaged by weevils and was found not attracted to the larvae of the weevils. This is a strong 
indication of influence of emitted volatiles (below or aboveground) for host location and presence. The roots only emit volatile when they are under insect attack. Specific volatile compounds that were studied include; $(E)-\beta-$ caryophyllene (sesquiterpene), dimethyl disulfide and $\beta$ copaene. A better understanding of how EPNs locates host insect can help to develop strategies to augment their efficacy in controlling soil pests (Turlings et al. 2012) [4].

White grubs appear at monsoon, soil $\mathrm{PH}$ and moisture have changed. System at field with sensors buried, as MQ-135 detects high level of $\mathrm{CO}_{2}$, a message is indicated on LCD. The message is exact location of insect via GPS module and send to famer's mobile number in the SIM 800 module. Location is recorded in longitude and latitude and interpreted using Google. The MQ-135 used to detect burst of $\mathrm{CO}_{2}$ by grub at $2^{\text {nd }}$ and $3^{\text {rd }}$ stage of instars mainly. EPN is natural enemy to white grub, is attracted by $\mathrm{CO}_{2}$ burst from grub and soil moisture, temperature, humidity sensors are employed to check the environmental conditions for early ( $1^{\text {st }}$ stage) infestation period of white grubs life cycle in the seasonal cycle [5]. This concept is shown below in figure 2 .

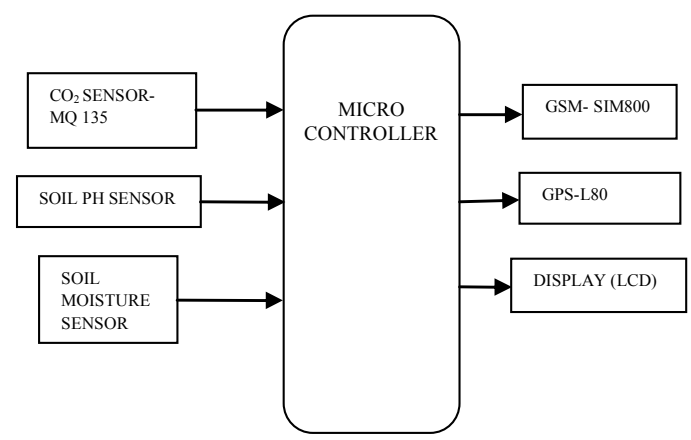

Fig. 2. The $\mathrm{CO}_{2}$ sensor white grub detection system.

The quantification of $\mathrm{CO}_{2}$ is difficult because of presence of other organisms in the soil that contribute to the amount of $\mathrm{CO}_{2}$ as part of soil respirations. Quality of the $\mathrm{CO}_{2}$ will be negatively associated for the white grub. The disadvantage of the calibration above is when used in an open environment; the sensors are exposed to fluctuating concentration levels and environmental conditions (temperature and humidity) affects the sensor response. The work by (S. De Vito et al.) addresses the problem of gas quantification in an open environment for urban pollution [6]. Figure 3. below shows $\mathrm{CO}_{2}$ and temperature relationship.

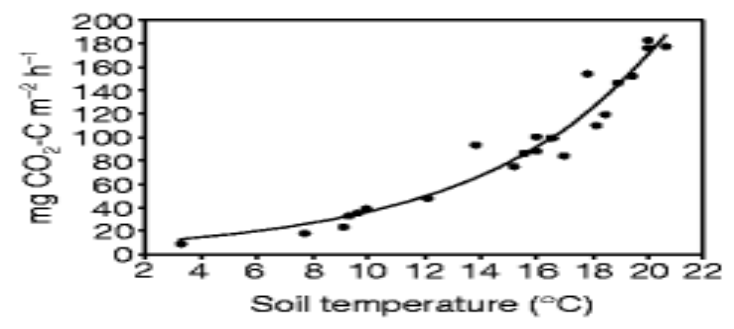

Fig. 3. $\mathrm{CO}_{2}$ versus soil temperature.

The acoustics systems was studied and presented mostly by entomologist who applied the technique of trained listeners to establish the presence of white grubs from the sound of their activities in the soil. The system was built with soil microphone, audio tape recorder, digitizer, filters and spectrum analyzer (spectrogram or oscilloscope) or by headphone. A lot is done by an expert (Richard W. Mankins et al.) for so many years to establish spectral templates for different insects as an entomologist in USADA (United States of America Department of Agriculture). Below is figure 4. for the process employed by entomologist (Richard W. Mankins et al.).

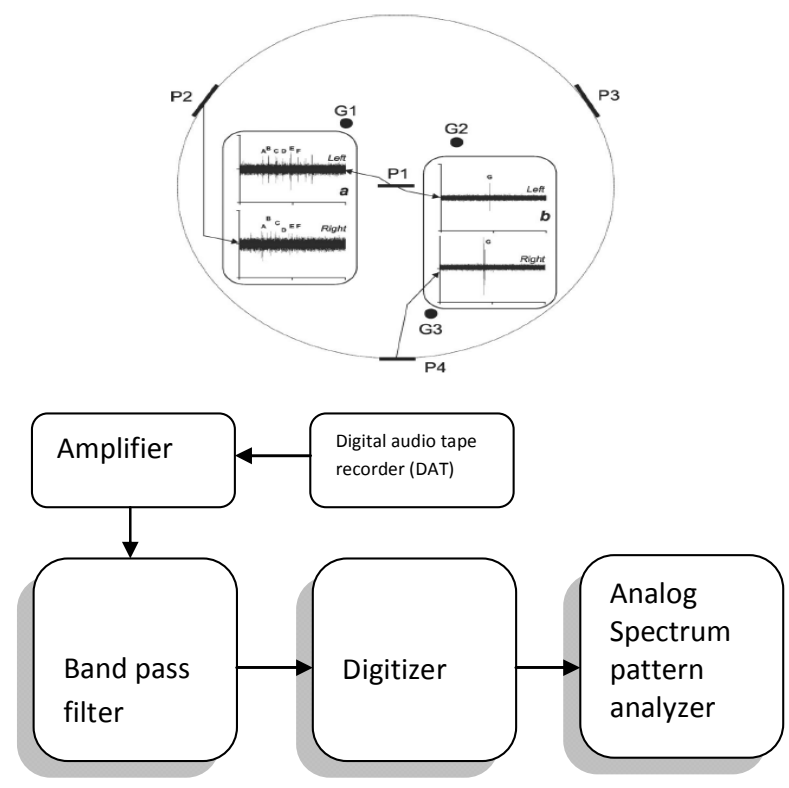

Fig. 4. Audio Master Kit (on-site) and sound analysis for frequency pattern (off-site)

To establish a spectral template for the presence of white grubs depends on electronic factors (attenuation and distortion) to environmental factors (soil type and structure). The system involves examining recordings from the field and ratings (low, medium and high) as compared to different techniques employed for observations in the recordings (sound pulse and listener) including excavation technique (cup-cutter). Figure 4. above showed the method employed by entomologist.

This paper studied the estimation of white grub by acoustic methods, the range of acoustic sensors, multisensory array field test and validation by soil sample of white grub at two (2) location of Texas. Single and four (4) sensor array were used with a dual channel audio tape recorder. Recording were made for three (3) minutes, but for high rate of sound recording was made for one (1) minute for easy access by listener and fifteen minutes recording for low sound rates for more assessment of different sounds. Mathematically estimation of white grub density is dividing the number of separate sources by the range of detection. Rate of attenuation is proportional to the frequency, also different frequency and different detection range from separate sources or locations. Rate of sound pulse determine number of insect population, but single recording does not account for the insect population density (sound pulse rate is proportional to number of insects) [7].

Each sound is counted as an insect sound pulse or a background noise based on verified temporal patterns (spectral) of grubs from previous studies (Mankin et al. 2001) [8]. Also to identify grub sound from previous findings that insect movement and feeding features are low intensity, short and different temporal pattern from background noise (Brandhorst-Hubbard et al. 2001), Mankin et al. 2000, 2001) [9].

Experienced listeners readily distinguished three types of sound with distinct differences in frequency and temporal 
patterns, intensities, and durations. It was studied that $7 \%$ of the sound was identified as clipping activity, $60 \%$ as surface sliding, $2 \%$ as surface scrapping and $31 \%$ as spectral pattern that is difficult to recognize. The detectable sound by Grubs depends on temperature, such that the lower the temperature the lower the sound rates by the Grubs and because of this it makes it less effective in cold weather. With the results obtained, it suggests that acoustic method can be applied as a nondestructive means of monitoring insects, and for biological or ecological studies. Previous acoustic methods were applied to detect presence or absence rather than to identify White Grub specific behavior or activity patterns. This study suggested two (2) different approaches to examine the behavior and activity pattern of white grub. The first method is to use acoustic technology to study the signals for the duration of a behavior or a specific feature that caused such a sound. The second approach is to study the conditions or treatment that caused an overall activity change of the white grubs using the acoustic technology. These changes can be environmentally, like temperature or from experiment. Some predictions were taken which includes; sound rate by white grubs would be proportional to temperature, sounds rate are proportional to weight for a given temperature and the relationship between temperature, weight and sound rate would be different for different species of white grub. An alternate method of testing of different sound rate at different temperature can be adopted and it was concluded that for the four species of white grub, it is difficult to use acoustic technique to examine them in the field for temperatures below $9^{0} \mathrm{C}$, but absence of repeated pulse at temperature above $28^{\circ} \mathrm{C}$. Acoustic techniques are expensive and time consuming, but are alternatives for nondestructive method of pest monitoring. Microphone together with digital signal processing can enhance detection and acoustic technique has shown the effect of environment on these insects and the laboratory effect as well [10].

\section{PROPOSED METHODOLOGY}

Since the $\mathrm{CO}_{2}$ system is considered as a generic signal to be detected from the activities of white grub, which comes from the idea of foraging cue of nematode (white grub natural enemy), is unreliable and has to be combined with a specific signal or other non destructive technique. In this case we shall combine volatile detection from roots of plants under insect attack as a specific signal with $\mathrm{CO}_{2}$ detection or with acoustic system. The whole three (3) sensors system can be combined for precise detection of white grub as shown in figure 5 . below.

A microcontroller system embedded on the sensor mote will coordinate the whole system for monitoring insect and the field condition. The field conditions are temperature, moisture and humidity. Laboratory test would be carried out, then to greenhouse test and to the farm field. The inputs of the system are the sensor values from the field and the output is the display of this parameters. Previously, these outputs were displayed on a liquid crystal display (LCD) and alarm or detection message with location is sent to a mobile phone via GSM and GPS modules. In this case, the parameters will be displayed on a graphical display using Laboratory Virtual Instrument Engineering Workbench (LabVIEW) combined with detection message to mobile phone. The microcontroller system takes in analog parameters from the field, convert to digital for processing and back to analog as output in case of acoustics, the other parameters will be in digital values (temperature, moisture, $\mathrm{CO}_{2}$ and volatile). There will be onsite devices (the sensors) and off-site devices the LabVIEW support. Digital values of temperature, moisture, $\mathrm{CO}_{2}$ and volatile will be sent, while analog values of frequency will be sent and displayed on off-site.

\section{Example of $\mathrm{CO}_{2}$ LabVIEW graphical program to use on programmable WSN node:}

The figure 6 . below shows the graphical form of program to use on the programmable WSN node or the compact Rio NI single board shown in figure 7. for $\mathrm{CO}_{2}$ sensing using GMM $221 \mathrm{CO}_{2}$ sensor.

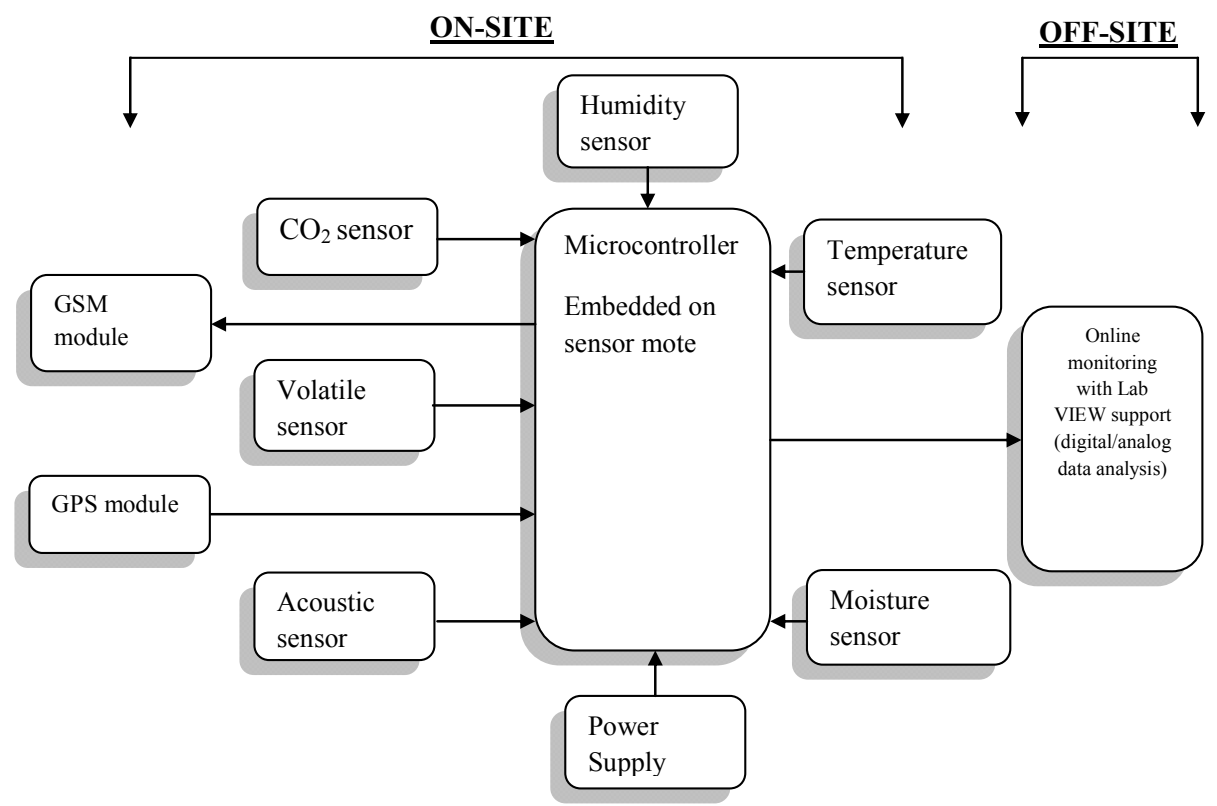

Fig. 5. The combine sensors system with LabVIEW support 


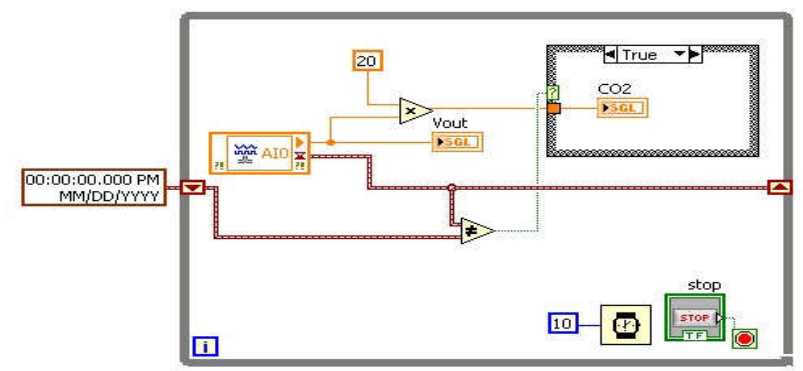

Fig. 6. Monitoring reading of GMM $221 \mathrm{CO}_{2}$ sensor Data in LabVIEW.

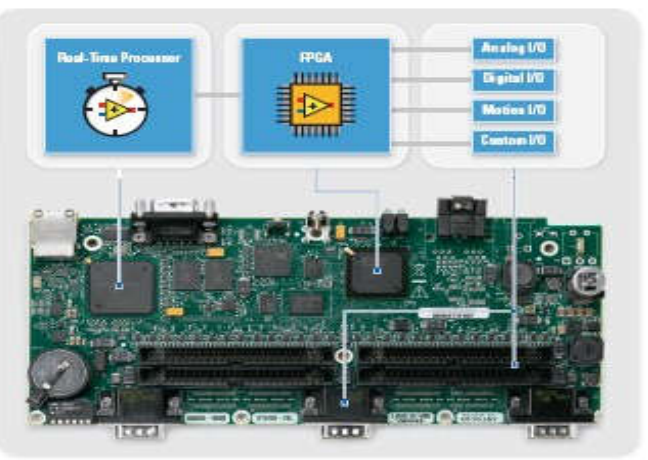

Fig. 7. NI single board RIO platform.

To calibrate the sensing of $\mathrm{CO}_{2}$ or the volatile compound we need a graphical component of the program of LabVIEW shown in figure 8 . below, which serves to perform measurement of the actual sensitivity of the sensor connected to the channel from end-to-end calibration on the selected channel and returns the measured sensor sensitivity. And figure 9. shows the acoustics (microphone) graphical program.

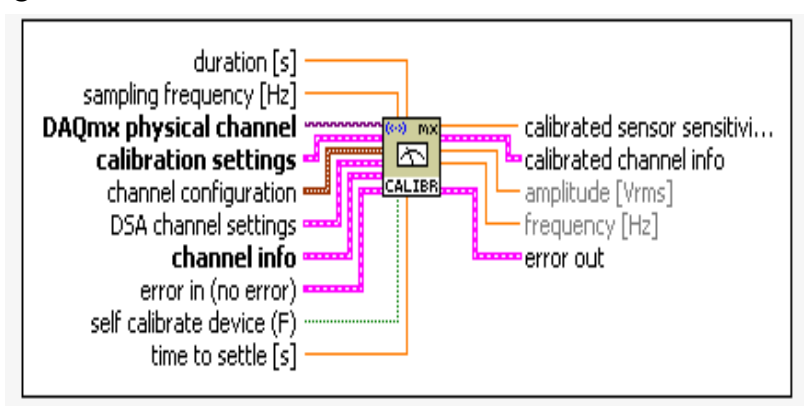

Fig. 8. Calibration program in LabVIEW

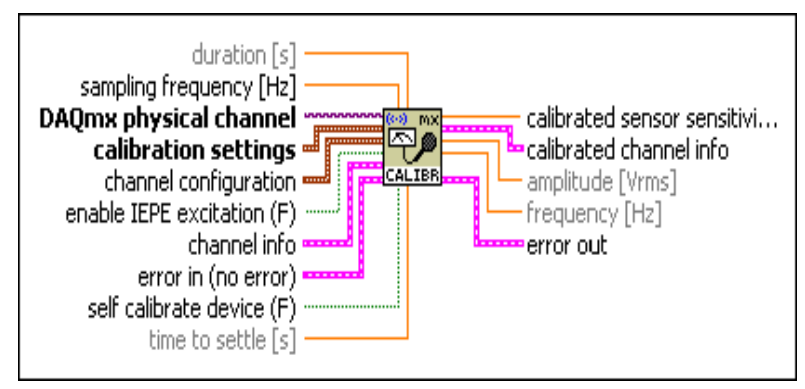

Fig. 9. The microphone graphical program in LabVIEW

\section{Result and analysis based on standard calibration response}

This section gives us the standard output or response of the $\mathrm{CO}_{2}$ sensing using GMM $221 \mathrm{CO}_{2}$ sensor, the acoustic measurement using the microphone with IEPE excitations. Figure 10. shows the standard response if extreme condition (rain or wet soil) is considered. The $\mathrm{CO}_{2}$ sensor signal with corresponding $\mathrm{CO}_{2}$ concentration is not linear, but is linearized by an internal linearization function. The probes simplify calibration and field services with flexibility of probes attachment, output options and different power supply. Figure 11. is the typical frequency response of a high sensitivity array microphone with nominal sensitivity of $50 \mathrm{mV} / \mathrm{Pa}$ and frequency response of $5 \mathrm{kHz}-20 \mathrm{kHz}$ (at $\pm 2 \mathrm{~dB}$ and $250 \mathrm{~Hz}$ ).

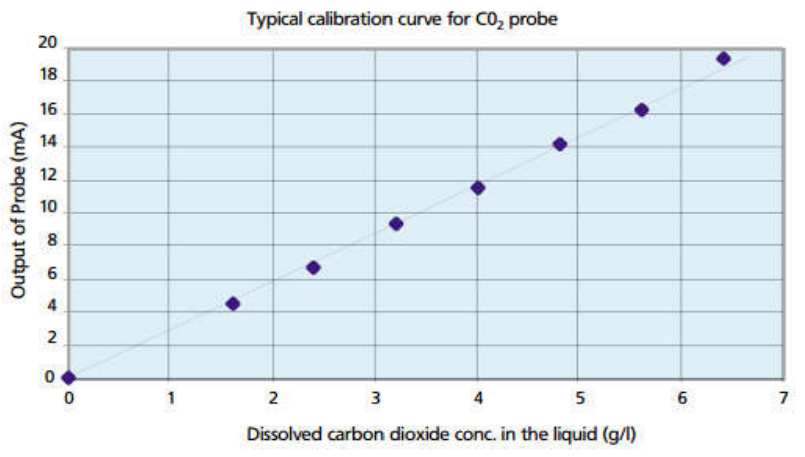

Fig 10 Typical linearized $\mathrm{CO}_{2}$ response.

High-Sensitivity Array Microphone Type 4OPH

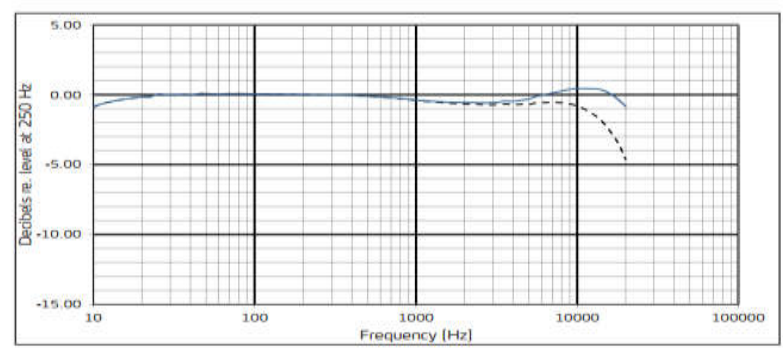

Fig 11 A typical frequency response with upper curve as free-field response.

\section{CONCLUSION}

These solutions will be implemented or conducted in phases from laboratory to green house and then to the field (open environment). With the LabVIEW, the $\mathrm{CO}_{2}$ can be calibrated and quantified in units with built in signal processing and data analysis. The acoustic pattern can be monitored continuously on real time with visual display and noise analysis. The established temporal and spectral template can be used to indicate presence of white grub.

The LabVIEW support has hardware and software standard for accuracy and compatibility for all sensors. The implementation of this is costly with LabVIEW but is an investment for reliable and precise detection of grubs.

\section{References}

1. Preeti Chawla, Rashid Hussain, "WSN application: Insect Monitoring through their behavior," International Journal of Advanced Research in Computer Science, ISSN NO- 0976-5697, Volume 6, No. 6, July-August, 2015.

2. S. Supekar and P. Mohite, "Utilization of entomophatogenic nematodes against the white grub, Holltricia serrata fab. Infesting sugarcane," Journal of Global Biosciences, ISSN 2320-1355, Volume 4, Number 8, 2015, pp. 3178-3181.

3. Richard W. Mankin, Clayton W. McCoy, Kathy L. Flanders, Jamee Brandhorst, Robert L. Crocker, and 
Jeffrey P. Shapiro, "Methods for Acoustic Detection of Insect Pests in Soil," Proceedings of the Soil Science Society of America Conference on Agroacoustics, Third Symposium, November 36, 1998, Buoyoucos, MS (3/31/2016).

4. Ted C. J. Turlings, Ivan Hiltpold, Sergio Rasmann, “ The importance of root-produced volatiles as foraging cues for entomopathogenic nematodes," Springer Science+Business Media B.V. 2012.

5. Glenes Concepta D'Mello and Rashid Hussain, "WSN Controlled Insects Monitoring: Identification of Location of White Grub," International Journal of Current Advanced Research Vol 5, Issue 7, pp 10781081, July 2016.

6. V. M. Hernandez bennetts, " Mobile Robots with Insitu and remote sensors for real world gas distribution modeling," Orebro University 2015, ISBN 978-91-7529-055-3, pp. 22-23, Orebro University 12/2014.
7. Minling Zhang, Robert L. Crocker, Richard W. Mankin, Kathy L. Flanders, Jamee L. and Brandhorst- Hubbard, "Acoustic Estimation and Population Densities of White Grubs (Coleoptera: Scarabaedae) in Turfgrass," J. Econ. Entomol. 96(6): 1770-1779, 2003.

8. Mankin R. W., S. L. Lapointe, and R. A. Franqui, "Acoustic surveying of subterranean insect populations in citrus groves," J. Econ. Entomol., 94:853-859, 2001.

9. Brandhorst-Hubbard, J. L., K. L. Flanders, R. W. Mankin, E. A. Guertal, and R. L. Crocker, "Mapping of soil insect infestations sampled by excavation and acoustic methods, J. Econ. Entomol., 94:1452-1458, 2001.

10. Minling Zhang, Robert L. Crocker, Richard W. Mankin, Kathy L. Flanders, Jamee L. and Brandhorst- Hubbard, "Acoustic Identification and Measurement of Activity Patterns of White Grubs in Soil," J. Econ. Entomol. 96(6): 1704-1710, 2003.

\section{How to cite this article:}

Yusuf Saleh and Rashid Hussain (2017) 'Intelligent System for White Grub Monitoring through WSN with LabVIEW Solution/Interface Support', International Journal of Current Advanced Research, 06(05),

pp. 3796-3801. DOI: http://dx.doi.org/10.24327/ijcar.2017.3801.0370 